\title{
“Destructive Communications" as a Factor of Threat to Pedagogical Employees' Occupational Health
}

\author{
Tetiana DZIUBA \\ Assoc. Prof. at the Department of General, Age and Practical Psychology \\ Ph.D. Candidate of Psychological Sciences \\ V.G. Korolenko Poltava National Pedagogical University, Ukraine \\ tatjanadzuba@gmail.com
}

\begin{abstract}
The article analyzes the results of a complex study on psychological prevention of threat to the health of the subjects in educational space. The main professional threats to the pedagogical employees' health in the educational organizations are analyzed by the parameter of information and communications in the structure of educational organization. It's emphasized that long-lasting discomfort in professional communications determines the exhaustion of organism's resources and changes of central coordinative mechanisms that lead to the restriction of the organism's adaptive abilities and after becomes the precondition for the development of different illnesses. A number of factors, including signs of communicative discomfort, can be treated as potentially possible threats for pedagogue's occupational health, are identified: criticism, especially unjustified, communicated in rude, humbling or mocking manner; mobbing (infliction of emotional distress at the working-place); negative forms of professional communications (problematic relationships with colleagues, parents, students, barriers in professional communication, unjustified aggression among collective members, internal group favouritism, gossiping etc.); conflicts in professional environment; authoritarianism (lack of tact and temperance, excessive selfconfidence, willingness to dominate etc.); intensive everyday stress; “inadequate" management style; envy among the collective members.
\end{abstract}

Keywords: communicative discomfort; destructive communications; threat of occupational health; mobbing; conflicts in a professional environment;

\section{Introduction}

Professional communications are an important component of professional pedagogical activity. They define the nature of interpersonal interaction of subjects in the educational environment. In the psychological interpretation, "communication" is defined as a psychological process of exchange of mental activity products (e.g. thoughts, feelings, emotions, knowledge), also as socializing, establishing and developing the contacts between people during their common activities (Gnatuk, 2010, p. 7). Ideal successful professional pedagogical communications cause the creation of comfortable conditions for interpersonal pedagogical interactions and full realization of communicative intentions and pedagogue's expectations. Abnormal communicative situations, where professional pedagogical communications develop discomfort characteristics, are the opposite.

Communicative discomfort in professional pedagogical communications causes the destruction of the mutual understanding in pedagogical contacts, abnormalities of verbal behaviour in pedagogical dialogue, provokes the occurrence of negative emotional and mental states among the communication participants. The pedagogue's choice of the wrong behavioural strategy becomes a threat of emerging of communicative anomalies (communicative failures, conflicts and misuses) (Fadeeva, 2014, p.73). 
Upon such conditions the communicative intentions and pedagogue's expectations lose the interoperability. It is important to emphasize that any communicative deviations prevent the neutralization of the negative influence of organizational, situational and personal factors on the nature of communication interactions, and violate "intersubjective recognition of pedagogue's claims for significance", i.e. for the validity, trueness and honesty (Habermas, 2000, p. 91).

The specified context gives grounds to consider the communicative discomfort in professional pedagogical communications as one of the most stress-producing types of pedagogue's mental activity. Besides that, the long-lasting discomfort in professional communications determines the exhaustion of organism resources and changes of central coordinative mechanisms state that appears in the activation of stress-realizing and limitation organism systems and leads to the restriction of its adaptive abilities, and after can become the precondition of different illnesses development.

The aim of article is the analysis of the approbation results of the author's technique "occupational health" by the scale "destructive communications" in the complex study of the problem of psychological prevention of threats to the health of the subjects of the educational space.

\section{Methodology}

The research is based on the concept of psychological ensuring of professional activity (Nikiforov, 2013; Shyngaev, 2014), the concept of pedagogue's personal-professional development and health (Mitina and Anasimova, 2005; Gaber, 2010).

The sample of the study had a total number of 1803 respondents, comprising of 374 men and 1429 women, aged from 20 to 57 years (with an average age of 33 years). The representativeness of the sample was established with the method of randomized selection. It was found in the data that the investigated population was characterized by the underrepresentation of the male subjects. Unequal distribution of the sample was considered to be an objective factor, given that the majority of the employees in the educational establishments are women. Data analysis was performed with a computeraided software package for statistical data analysis, IBM SPSS Statistics 21.

Significant relationships between components of the scale "Destructive communications" (technique "Occupational health" - Dziuba, 2015) and indicators of emotional burnout (Boyko, 1996), level of subjective well-being (Sokolova, 1996, cited in Nikiforov, 2011), sensitivity to crisis manifestation and crisis states (Azarnych and Tartyshnikov, 1999) and detection of neurotic states (Yakhin and Mendelevich, 1999) are analyzed.

\section{Results and Discussion}

Destructive communications are the threats to the pedagogues' occupational health in the case of intensification of all the symptoms of burnout and reinforcement of subjective experiences, and may provoke a crisis of competence and a professional development crises, professional destruction and deformation of the employee. 
A complex study of occupational threats to the health of the pedagogical employees in educational institutions led to the necessity of the development and testing of author's technique "Occupational health" (Dziuba, 2015), which made possible the analysis of the major occupational health threats to pedagogues by the following parameters: organization of the professional environment (forms of tasks distribution among the pedagogical employees; the implementation of tasks and orientation to goals; forms of motivation and labour organization; consistency of rights and responsibilities); information and communications in the structure of professional organization (evaluation of the main forms of information transfer; evaluation of the correctness of the management orders; feedback level score; effective professional interaction); professional self-actualization (evaluation of the individual's own professional resources and opportunities; personal integrity; professional self-sufficiency).

Psychometric approbation of the technique "Occupational health" showed the high reliability and validity of the psycho-diagnostic toolkit $(\mathrm{p}<0.000000$ with $\mathrm{N}=1803$ ) (Dziuba, 2015, 2016). As a result of the confirmatory factor analysis conducted of the questionnaire's internal structure, four scales were determined: "Destructive communications", "Destabilizing organization of professional activity", "Destruction of professional self-affirmation", and "Demotivators of labour productivity" (see Table 1).

Table 1. The results of confirmatory factor analysis of the questionnaire's “Occupational health" internal structure

\begin{tabular}{|l|c|c|c|}
\hline \multirow{2}{*}{ Determined scales } & Sum & $\begin{array}{c}\text { Contribution to } \\
\text { the sample } \\
\text { variance }\end{array}$ & $\begin{array}{c}\text { Total contribution } \\
\text { to the sample } \\
\text { variance }\end{array}$ \\
\cline { 2 - 4 } & 8.35 & $28.78 \%$ & $28.78 \%$ \\
\hline $\begin{array}{l}\text { "Destructive communications" } \\
\text { professional activity" }\end{array}$ & 2.79 & $9.61 \%$ & $38.39 \%$ \\
\hline $\begin{array}{l}\text { "Destruction of professional self- } \\
\text { affirmation" }\end{array}$ & 2.28 & $7.86 \%$ & $46.25 \%$ \\
\hline $\begin{array}{l}\text { "Demotivators of labor } \\
\text { productivity" }\end{array}$ & 1.78 & $6.13 \%$ & $52.38 \%$ \\
\hline
\end{tabular}

Source: Own research

The highest factor load was obtained by the scale "Destructive communication" $(28.78 \%$ contribution to the sample variance), which brings together a number of factors that directly or indirectly can be defined as including the signs of communicative discomfort and, under our assumption, can be treated as potentially possible threats to the pedagogue's occupational health: F25 - critic, especially unjustified, communicated in rude humbling or mocking manner (0.752); F13 - mobbing (infliction of emotional distress at the working-place) (0.746); F3 - negative forms of professional communications (problem relationships with colleagues, parents, students, barriers of professional communication, unjustified aggression among collective members, internal group favouritism, gossiping etc.) (0.744); F15 - conflicts in professional environment (0.724); F23 - authoritarianism (lack of tact and temperance, excessive self-confidence, willingness to dominate etc.) (0.644); F11 - intensive everyday stress (0.620); F14 "inadequate" management style (0.599); F12 - envy among the collective members (0.580).

Let us focus deeper on the analysis of the significant relationships among the components of the scale "Destructive communications" (Dziuba, 2015), indicators of the burnout (Boyko, 1996) and the level of subjective well-being (Sokolova, 1996, cited in Nikiforov, 2011). 
A high level of correlation tendencies for the factor «critic, especially unjustified, communicated in rude humbling or mocking manner» is consistent with certain personal dispositions, such as: self-dissatisfaction (.464*) as a factor, which changes the employee's professional position through the decreasing of professional motivation and labour efficiency and leads to professional fatigue, degrading of repertoire of professional activity fulfilling methods, etc; excessive anxiety $\left(.456^{*}\right)$, and tendency to depression $\left(.372^{*}\right)$, as factors of professional mal-adaptation, which cause the appearance of possible conflicts in professional "I-concept" through activation of fear of encroachment on integrity of image "I-professional", loss of professional status, authority, etc; emotional and moral disorientation $\left(.557^{*}\right)$ as intensification of inadequate reaction in professional relationships, absence of appropriate emotional attitude to the partner in interaction, situation of fulfilling the professional duties depending on the mood and subjective preferences; distancing (.607) as a variant of emotional sphere expansion; emotional deficit $\left(.555^{*}\right)$ as inability to provide help to the subjects of professional activity; inadequate emotionally selective response $\left(.783^{* *}\right)$ as inadequate emotional "scarcity", limitation of emotional response by the principle "want - don't want" - in inadequate or selective way; tendency to "being cornered" (.416**) as a state of intellectual and emotional block, desperation. The danger in fixing these identified tendencies is that the situation of an unnecessarily hostile, critical attitude creates the undermining of confidence of employees in their own professional abilities and opportunities, dissatisfaction with the results of their work, their professional status, the propensity to self-accuse, or to accusation of others.

Factor «mobbing (infliction of emotional distress at the workplace)» shows high correlation relationships with such symptoms of burnout as self-dissatisfaction $\left(.466^{* *}\right)$, "being cornered" $\left(.390^{* *}\right)$, emotional and moral disorientation $(.712 *)$, reduction of professional duties $\left(.391^{*}\right)$ and emotional alienation $\left(.686^{* *}\right)$. That is, in the situation of mobbing an employee experiences negative emotional states, directly or indirectly, is exposed to emotional violence, is constantly degraded and is often unjustifiably put on charges. Reduction of professional duties in the situation of mobbing may manifest itself as an attempt to alleviate or reduce one's own professional duties that require excessive energy expense. Emotional isolation indicates a high level of emotional discomfort, loss of trust in others, difficulty in control over emotional states, as evidenced by the presence of statistically significant correlations for the scales "level of subjective well-being" ($\left..663^{* *}\right)$ and "sensitivity to the crisis" $\left(.669^{* *}\right)$. Therefore, we can state that in the situation of mobbing the professional environment not only aggressively affects the employee, it also destructively impacts individual senses of personal professional being, causing professional risk to the employee's occupational health. The consequence of this is usually a reduction of professional communications, psychological trauma, professional crisis and even dismissal of the employee.

With the factor «negative forms of professional communications» we received direct significant correlations with such symptoms of burnout as an extension of the sphere of emotions savings $\left(.612^{*}\right)$, emotional shifts $\left(.690^{* *}\right)$, sleep cycle disruptions $\left(.686^{* *}\right)$ and vegetative disorders $\left(.588^{* *}\right)$, proving the destructive effects of negatively stained professional communications not only on the physical and psychological health, professional and personal development of the employee, but also the presence of prolonged stressful professional reality.

The factor «conflicts in a professional environment» showed a positive correlation with the following symptoms of burnout: experiences of psychotraumatic circumstances $(.630 * *)$, self-dissatisfaction $(.754 * *)$, "being cornered" $\left(.578^{* *}\right)$ in the phase of tension 
$(.554 *)$; inadequate emotional selective reaction $(.747 * *)$ and reduction of professional duties $\left(.889^{* *}\right)$ in the phase of "resistance" $\left(.412^{* *}\right)$; emotional scarcity $\left(.420^{* *}\right)$, emotional alienation $\left(-.483^{* *}\right)$, depersonalisation $\left(.786^{*}\right)$ and psychosomatic and psychovegetative disorders $\left(.557^{* *}\right)$ in the phase of "exhaustion". This shows that conflicts in professional pedagogical activity are a powerful stressor, impact the personality and emotional changes of the employee, and can promote the growth of helplessness and loss of interest in the content of the professional activity.

With the clinical questionnaire for detection and estimation of neurotic states the statistically significant indicators by scales "asthenia" (-.511**) and "vegetative disorders" (.854**) were obtained. According to Chernus and Shatihin (2009, p.30), asthenia is the equivalent of the "emergency brake", which prevents the full loss of employability. In this context, asthenia is regarded as the universal organism reaction to any state, which is a threat of energy processes exhaustion. Such a point of view explains fully the presence of a negative statistically significant correlation of factor with the scale "asthenia".

Essential characteristics of negative professional communications are their variety, intensity, unpredictability and aggressiveness. The lasting impact of negatively stained professional communications can cause destructive attitudes such as veiled or open violence, rumbling, negative experiences in communications, which provoke the employee to react inadequately or inappropriately in professional interpersonal communications, and under special circumstances can receive a particular personal significance, becoming fixed.

On the general background, the indirect correlations of factors with indicators from the questionnaire of detection and estimation of neurotic states (Yakhin and Mendelevich, $1998)$ are especially distinctive, in particular: "anxiety" (-.619**), "neurotic depression" $(-.439 * *)$, "asthenia" $\left(-.681^{*}\right)$, "hysterical reaction type" $(-.889 *)$, of which trigger ${ }^{1}$ is negative relationships in professional communications. Thus, negative forms of professional communication are characterized by the subjective evaluation of interpersonal interaction and can become the foundation for interpersonal professional stress and temporarily impair an individual's ability to effectively carry out their professional activities. At the same time, they become a favourable basis for identifying the crises of professional identity, the inadequate and ambiguous employee's perception of his professional "I". So, negative professional communication can contribute to the development of the pre-neurotic states, raise the risk of functional capacities exhaustion of the nervous system under overexertion, and increase the level of somatic morbidity threats.

The factor «authoritarianism, lack of tact and temperance, willingness to dominate, authoritarian aggression» has a positive correlation with certain indicators of burnout ("inadequate emotional selective response" (.797**), "personal alienation (depersonalization)" (.678*), "being cornered" (.686**), "emotional deficit" (.527**)). At the same time there is an interesting tendency of indirect correlations of factor with the indices of the clinic questionnaire of detection and estimation of neurotic states (Yakhin and Mendelevich, 1998): "anxiety" (-.554**), "neurotic depression" (-.430**), "asthenia" $(-.798 * *)$ along with a positive statistically significant correlation with the index "vegetative disorders" (.793*). Thus, the observed correlations capture the phenomenon

${ }^{1}$ Trigger - experience, which again begins the psychic trauma through the form of flashbacks and intense feelings of sadness, anxiety or panic. The brain forms connections between the trigger (starting the reaction) and feelings with which it is associated. 
of authoritarian attitude in pedagogue's professional communications, that directly or indirectly affect the well-being (-.667) of the employee.

The next area of threats to pedagogical employees' occupational health in educational organizations by the scale "Destructive communications" is the factor «intensive everyday stress». Professional stress is considered to be unspecific organism reaction to the influence (physical or psychological) of the professional environment that disturbs homoeostasis and becomes the source of potential professional psychological risks of the employee's occupational health. From the results of the correlation analysis, the relationships between the factor "intensive daily stress" and indicators of emotional burnout (Boyko, 1996) were observed. In particular, experiences of psychotraumatic circumstances $(.469 * *)$, "being cornered" $\left(.452^{*}\right)$, "anxiety and depression" $\left(.786^{* *}\right)$ in the phase of tension $\left(.511^{* *}\right)$; inadequate emotional selective reaction $\left(.783^{* *}\right)$ and reduction of professional duties $\left(.453^{* *}\right)$ in the phase of "resistance" (.794**); emotional alienation $\left(.635^{* *}\right)$, depersonalisation $\left(.876^{*}\right)$, psychosomatic and psychovegetative disorders $\left(.585^{* *}\right)$ in the phase of "exhaustion" $\left(.444^{* *}\right)$. Therefore, almost all indicators of burnout syndrome show statistically significant correlations. This tendency determines the intensive everyday stress as a specific feature of professional pedagogical activity, the result of a variety of occupational stressors, especially of interpersonal nature and is a risk to burnout and loss of employee's occupational health.

Let us discuss the factor «inadequate» management style. Under the "inadequate" management style we understand the system of management influences which directly or indirectly destabilize the inner world of the employee, causing the state of "chronic mobilization", emotional exhaustion, making him/her be constantly "alert". In this situation the employee gets quickly exhausted, as he/she is constantly forced to respond to diverse, including disorganizing, changes in organizational environment. In the course of study the negative correlations between the factor and scale of subjective well-being (Sokolova, 1996, cited in Nikiforov, 2011) (-.795**) were observed, as well as positive correlations with indicator "sensitivity to the crisis" (.663**) (Azarny and Tartišnikov, 1999) and the scale of anxiety (Yakhin and Mendelevich, 1998) (.441**). The observed tendencies are completed with a number of correlations between "inadequate" management style and the indicators of emotional burnout: experiences of psychotraumatic circumstances $\left(.493^{* *}\right)$, "being cornered" $\left(-.596^{* *}\right)$, in the phase of tension $\left(.484^{* *}\right)$; inadequate emotional selective reaction $(.649 *)$, reduction of professional duties $\left(.677^{* *}\right)$ in the phase of "resistance" $(.407 * *)$; emotional alienation (.277**), emotional scarcity $\left(-.510^{* *}\right)$, depersonalisation $\left(.314^{* *}\right)$ and psychosomatic and psychovegetative disorders $\left(.469^{* *}\right)$ in the phase of "exhaustion" $(.407 * *)$. Thus, the "inadequate" management style is one of the varieties of organizational factors for occurrence of burnout syndrome and crisis of professional development.

It's worthwhile to notice the presence of a large number of significant correlation links between indicators of burnout syndrome in the phase of exhaustion and "inadequate" management style. In particular, an "inadequate" management style is negatively related to the indicator emotional scarcity $\left(-.510^{* *}\right)$, and - positively related to indicators emotional alienation $\left(.277^{* *}\right)$ and depersonalisation $\left(.314^{* *}\right)$. This tendency contributes to exhaustion and simplification of the employee's emotional sphere due to stiffness and formality of the relationships with the supervisor, suppression of the employee's initiative, and as a result - awareness of the employee's own ineptitude in emotiogenic situations. This symptom describes the presence of conscious non-emotional responses in official situations, and is an indicator of professional deformation. 
Concerns are caused by the cases of demonstrative emotional alienation, in which employees exhibit indifference and no involvement in communication situations. Depersonalisation is characterized by a loss of interest by the individual as to the object of professional communication. Considering the total dependence of pedagogical employee's professional achievements on the peculiarities of communication, we can conclude about the extremely negative impact of this symptom on the effectiveness of the professional pedagogical activity. Therefore, the analysis of the interconnection between the signs of emotional burnout and "inadequate" management style shows a generally unfavourable prognosis in the form of employees' neurotic development: strengthening of accentuations of personality traits, general decrease in adaptive capabilities and psychosomatic disorders.

The last factor, included in the scale "Destructive communications", is the factor «envy among the collective members». Significant positive and negative correlations of the factor were observed with the following scales: scale of subjective well-being (Sokolova, 1996, cited in Nikiforov, 2011) (-.560**); "hysterical reaction type" (.406**), "vegetative disorders" $\left(.510^{* *}\right)$, "neurotic depression" $\left(.238^{* *}\right)$, "obsessive - phobic disorders" $(.257 * *)$ (Yakhin and Mendelevich, 1998); by indicators of emotional burnout: experience of psychotraumatic circumstances $\left(.882^{* *}\right)$, "being cornered" $(.544 *)$, anxiety and depression $\left(.206^{* *}\right)$ in the phase of tension $\left(.447^{*}\right)$; reduction of professional duties $(.351 *)$ in the phase of resistance; personal alienation (depersonalisation) $(.820 * *)$, emotional alienation $\left(.611^{* *}\right)$, psychosomatic and vegetative disorders $\left(.454^{* *}\right)$ in the phase of exhaustion (-.786**) (Boyko, 1996).

Analysis of the identified tendencies shows that the phenomenon of envy, being one of powerful regulators in professional pedagogical communication, updates the emergence of emotional, behavioural and psychosomatic deviations. According to the definition by Beskova (2011), envy is the personal destruction which is revealed through an attitude to another person, determining the subjective assessment of his/her benefits in significant areas, and is accompanied by a set of negative emotions, decreased self-esteem and desire to neutralize the advantages of another. So, envy as a professional destruction creates the problem of pedagogical employees' mental health: forms dissatisfaction with the profession, enhances the emotional burnout due to the activation of the well-known psychosomatic syndromes (asthenization - feeling the constant fatigue, tiredness, nervous exhaustion; the worsening of mood with easy emerging anxiety; sleep deprivation, etc.), distorts the integrity of professional I-concept, violates the professional adaptation. The observed tendencies are confirmed by the results of empirical research by Beskova and Shaminov (2011), where it is shown that the "dissatisfaction of the individual... only enhances his/her envy, becoming a reason to search (or the active neglecting the benefits) the object of envy. This does not indicate that the envy person and the one who is making efforts towards the object of envy are not satisfied. However, a full picture of the subjective well-being of these individuals is not built up..." (Beskova and Shaminov, 2011, p. 18). Thus, the envy in the professional pedagogical communications destructively impacts the employee's mental health and appears in unproductive behavioural patterns, aggressiveness, and proneness to conflict or irrational agreeableness. 


\section{Conclusion}

The destructive tendencies in professional pedagogical communications inevitably lead to the tension, significantly affecting the level of the pedagogue's occupational health. Depending on the strength, periodicity, persistence of them and the individual characteristics of the psychological resistance, pedagogue can form unproductive behavioural patterns, numerous disorders of psychological and physical nature (burn-out syndrome, nervous break-downs, sleep disruptions, chronical annoyance, etc.), intensification of character accentuations, general decrease of the adaptation abilities. The destructive communications disturb heavily the pedagogue's occupational health and affect the performance quality, weaken the group unity, lead to emotional expenditures, psychological discomfort in professional communications, dissatisfaction in the profession.

The danger of the fixing of the observed tendencies is that the destructive communications cause the personality destructions, e.g. authoritarianism or enviousness, which also find expression in communicative dysfunctions: weaken the contacts with other participants of the educational process, complicate the realization of own needs and goals by the pedagogue. Along with this the personality destructions can obtain the concealed forms, which are difficult or impossible to be detected by the employee. The dominance of the destructive tendencies leads to the step-backs from the reality, the ruination of social contacts, closeness in communication, blocking the sensory sphere.

Therefore, the obtained results of the study on the sample from the educational organizations in Ukraine show that the professional pedagogical communications are characterized as those where the employee is affected by the numerous variable and intensive stressors. They can provoke and determine the context of the threat zone (risk factors) for the health of all subjects in educational space.

\section{References:}

Azarnykh, T.D., Tyrtyshnikov, I.M. (1999): Psychological Health (Questions of Valeology): study guide. Voronezh: MODEK.

Beskova, T.V. (2011): Socio-demographic structure of enviousness. Social Psychology: 1, 57-69. Retrieved from http://chsu.kubsu.ru/arhiv/2011_1/2011_1_Beskova.pdf

Beskova, T.V., Shaminov, R. M. (2011): Peculiarities of subjective well-being of envy and competition subjects. Russian psychological journal 8(2): 9-18.

Boyko, V.V. (1996): Energy of emotions in communications: look at oneself and others. Publishing house "Philin".

Chernus, N.P., Shatikhin, A.I. (2009): Syndrome of functional asthenia in common therapeutic practice. Difficulties of diagnosis and therapy. Difficult patient 7(6-7):29-34.

Dziuba, T.M. (2015): Complex of techniques for diagnosis of teacher's occupational health. Poltava: V. G. Korolenko Poltava National Pedagogical University.

Dziuba, T.M. (2016): Psychometric analysis of development and testing of technique "The risks of occupational health". Bulletin G. S. Skovoroda Kharkiv National Pedagogical University. Psychology 53: 47-56. doi: dx.doi.org/10.5281/zenodo.44712.

Fadeeva, E.V. (2014): Methods of language expression of communicative discomfort on different levels of linguistic analysis. Bulletin MSRU. Series “Russian philology” 3:66-73. 
Gaber, I.V. (2010): Formation of teacher's health-preserving competence in the educational process of institutions of additional education. Competency update at different levels of education. Collective monograph, ed. S.I. Pozdeeva. Tomsk - Publishing house TGPU.

Gnatiuk, O.L. (2010): The basics of communication theory: learning guide. KnoRus.

Habermas Y. (2000): Moral consciousness and communicative action. St. Petersburg: Science.

Mitina, L.M., Anisimova, O.A. (2005): Teacher's professional activity and occupational health. Academy.

Nikiforov, G.S. (Ed.) (2013): Scale of subjective well-being (M. V. Sokolova). Diagnosis of health. Psychological practical work. St. Petersburg: Speech. p. 376-378.

Shingaev, S.M. (2014): Psychological support of managers' occupational health. Abstract of the doctoral dissertation. St. Petersburg.

Sokolova, M.V. (1996): The scale of subjective well-being: the handbook. Yaroslavl: SPC Psychodiagnostics.

Yakhin, K.K., Mendelevich, D.M. (1998): Clinical questionnaire for the identification and assessment of neurotic states. Clinical and medical psychology: pract. manual. MED-press. 